\title{
A geopolítica dos recursos naturais da Rússia: Uma análise sob a perspectiva de Vladimir Putin
}

\author{
Débora Nascimento Chagas ${ }^{1}$
}

Resumo: Este trabalho pretende revisar a geopolítica russa de seus recursos naturais e como esta influencia na atuação do país no contexto internacional. Os recursos naturais desempenham papel de extrema importância na geopolítica global, desde o fim do Século XIX. Todas as grandes potências, que já detiveram importantes posições no cenário global, buscam independência de outros Estados no que tange o abastecimento energético, mesmo que seja necessário construir meios de dominação dos recursos naturais de países sem condições de explorá-los. A Rússia não fica atrás quando de trata de administrar seus recursos energéticos, especialmente com a chegada de Putin a Presidência. $\mathrm{Na}$ verdade, a estratégia geopolítica russa compreende-se na boa administração de seus recursos naturais para que se mantenha como agente preponderante no cenário internacional, a ponto do Estado intervir diretamente nas regras do jogo da indústria do petróleo e do gás. Palavras-chave: Rússia, Petróleo e Gás, Putin, Geopolítica.

Abstract: This paper aims to review Russian geopolitics and its influence on its actions as an international agent. Since the last decades of the century XIX the energetic natural resources have been playing an essencial role within the global geopolitics. Every big player who holds or held an important position within the international context, seeks for independence from others when it comes to energetic resources eventhough it means to subdue weaker players by exploiting their natural resources as they don't have ways to do it by themselves. Russia isn't held back while conducting its natural resources, specially with

\footnotetext{
1 Graduanda de Relações Internacionais pelo Centro Universitário Uninter, Curitiba/PR.
} 
Putin as its President. Indeed, Russia's geopolitical strategies relies on the good management of its reserves in order to preserve its position as a rulling player within the international relations, which makes the State directly step in and control the rules of the game on Russian Oil \& Gas industry.

Key words: Russia, Oil \& Gas, Putin, Geopolitics.

\section{Introdução}

O presente artigo tem por objetivo tratar a geopolítica russa dos recursos naturais e como se trava o jogo do poder entre o Estado russo e as empresas privadas que atuam dentro de seu território. Além disso, este pretende compreender como a posse de grandes reservas de petróleo e gás influenciam na atuação política internacional russa e na sua tentativa de se reinserir no grupo das grandes potências globais.

Com a entrada de Vladimir Putin na presidência em 2000, as estratégias russas tomaram um novo rumo, frente a defesa dos interesses do país, o que vem trazendo a Rússia de volta as discussões internacionais e incomodando o ocidente. Este trabalho tentará mostrar que a mudança na estratégia geopolítica russa ocorre de várias maneiras, desde que Putin tornou-se presidente. Este conseguiu restabelecer o controle da Rússia nas mãos do presidente, diferentemente do que acontecia no governo de Boris Yeltsin.

As grandes reservas de petróleo e de gás da Rússia servem como fonte de renda para investimentos na economia e na indústria do 
país. E Putin parece estar dedicado em tirar o máximo de vantagens deste lucrativo e potencial instrumento de poder.

A construção deste artigo utilizou a pesquisa de artigos relacionados ao temas e publicados por renomadas Universidades Internacionais, tais como, Harvard, Standford e a Rice University. Além destes foram considerados estudos realizados por centros internacionais de estudos dos recursos naturais, como exemplo o Instituto de Estudos Energéticos do Japão.

A condução da pesquisa, inicialmente, direcionou-se através da construção de um panorama histórico para compreensão da inserção dos recursos naturais nos jogos de poder globais desde o fim do Século XIX. Além da pesquisa histórica, foi adotado um método de pesquisa indutivo, com o intuito de corroborar a defesa da hipótese apresentada com as atitudades da Rússia em sua geopolítica.

A hipótese, pautada em estudo de recentes matérias públicas em renomadas revistas internacionais, dentre elas a The Economist e o Le Monde Diplomatique, finaliza o trabalho através da análise sistêmica da conjuntura em que a Rússia está inserida, tornando possível a construção de um pensamento dedutivo que conecte as ações do Governo de Putin com a conclusão deste trabalho, que defende a intenção russa de reinserção no cenário geopolítico internacional dentre as potências que regem o sistema. 
Na primeira parte deste artigo abordará brevemente a história do petróleo e como foi a inserção deste recurso no cenário econômico internacional a partir do final do Século XIX. A segunda parte disponibilizará o contexto o qual os recursos naturais se tornaram preponderantes na geopolítica global, através do panorama histórico da iminência da Segunda Guerra Mundial. A terceira parte observará como a Rússia se comporta geopoliticamente quando administra suas fontes de recursos naturais e como se pautam suas ações de influência regional pelo controle das reservas e abastecimento de gás natural na Eurásia. Por fim, a quarta parte verificará a influência do Presidente Vladimir Putin frente as estratégias russas na administração de seus recursos, bem como na maneira em que as utiliza para se reinserir como ator preponderante no cenário internacional.

\section{Petróleo: $o$ início da corrida global pelo ouro negro.}

O petróleo, de acordo com o Departamente de Engenharia da UNICAMP, é uma substância oleosa, inflamável, com cheiro característico e, em geral, menos densa que a água e com cor variando entre o negro e o castanho escuro. A substância origina-se da decomposição dos seres que compõem o plâncton e é resultante da pouca oxigenação e da ação de bactérias. Ao longo de milhões de anos estes seres foram se acumulando no fundo dos mares e dos lagos e se 
transformaram no que conhecemos, hoje, por petróleo. Este se desloca até encontrar um terreno apropriado para se concentrar, ou seja, até as bacias sedimentares, formando jazidas. Nestas pode-se encontrar o gás natural, na parte mais alta, e o petróleo e água nas partes mais baixas (DPF/UNICAMP).

Desde a antiguidade, o petróleo surgia de maneira natural em alguma regiões que correspondem atualmente ao Oriente Médio. Era usado para diversos fins, tais quais: para colar ladrilhos, engraxar couros, embalsamar e lubrificar as rodas das carruagens. Aponta-se o século XIII como o início da produção em escala comercial do petróleo, naturalmente com as limitações da época, quando Marco Polo viajou pelo norte da Pérsia em 1273 e registrou o uso do petróleo na iluminação e para usos medicinais. Em 1850, antes mesmo do petróleo tomar as proporções comerciais que atualmente protagoniza, a substância era usada como laxante, cicatrizante e anti-séptico. Ainda, era considerado eficaz no tratamento da surdez e na cura de tosse, bronquite, congestão pulmonar, gota, reumatismo e mau-olhado (MBP/COPPE/UFRJ).

Em 1854, um grupo de investidores contratou o professor de química da Universidade de Yale, Benjamin Silliman Jr. para analisar as propriedades do óleo como iluminante e lubrificante (MBP/COPPE/UFRJ). Somente no ano de 1859, com Edwin Laurentine Drake, é que o petróleo foi extraído pela primeira vez do 
subsolo, através de uma técnica de perfuração, em Titusville no estado da Pensilvania. Naquela época o óleo de pedra, como era chamado então, poderia ser exportado em quantidade e processado para ser convertido num fluido que seria queimado em lampiões, como iluminante, de forma a competir com óleos de carvão, que detinham o monopólio do mercado. O plano de inserção deste produto no mercado, consistia, seu custo benefício, pois utilizava-se menos óleo para uma iluminação de boa qualidade e barata. Passados cinco anos, achavam-se constituídas, nos Estados Unidos, 543 companhias entregues ao novo e rendoso ramo de atividades. Na Europa floresceu, em paralelo a fase de Drake, uma reduzida indústria de petróleo, que sofreu a dura competição do carvão, linhita, turfa e alcatrão, até então entendidas como nobre.

Em 1870, John D. Rockfeller ${ }^{2}$ inaugura a Standard Oil em parceria com seu irmão William Rockfeller, Henry Fagle, Jabez Bostwick, Stephen V. Harkness e o químico Samuel Andrews. O sucesso da demanda de querosene e gasolina favoreceu o rápido enriquecimento de Rockfeller, que se tornou o homem mais rico do mundo e o primeiro americano a ter mais de um bilhão de dólares. A S.O. se tornou, muito rapidamente, uma das maiores trasnportadoras de

2 John D. Rockefeller, fundador da Standard Oil, da Universidade de Chicago e da Universidade Rockefeller. Sua fortuna total foi estimada, em 1937 (ano de sua morte), em 1,4 bilhão de dólares, se tornando o homem mais rico da história (MBP/COPPE/UFRJ). 
petróleo e querosene dos Estados Unidos e obteve quase que o monopólio do mercado de extração e refino dos Estados Unidos na época (TARBELL, 1904).

A Royal Dutch-Shell Group, de capital anglo-holandês e apoiada pelo governo britânico, expandiu-se rapidamente no início do século XX, passando a controlar a maior parte das reservas conhecidas do Oriente Médio. Posteriormente, a empresa passou a investir na Califórnia, no México e na Venezuela. Neste mesmo tempo, companhias européias promoveram muitas pesquisas em todo o Oriente Médio e destas concluiu-se que a região detinha, em seu território, cerca de setenta por cento das reservas mundiais o que provocou reviravoltas em todos os planos de exploração. Iniciava, então, a corrida pela posse e extração do ouro negro ao redor do globo (CEPA - IF - USP).

Enquanto isso, na Rússia, os irmãos Nobel transformaram o Canto de Baku, situado às margens do Mar Cáspio, em uma verdadeira Meca do petróleo, construindo casas apropriadas para seus trabalhadores e condições decentes de trabalho para estes. Além de terem revolucionado ao construírem as primeiras refinarias privadas, assentarem o primeiro oleoduto e distribuirem o petróleo russo através de navios petroleiros construídos por eles mesmos; mostraram integridade, honra e benevolência em seus negócios. O clã dos Nobel deixou seu legado honesto e pacífico ao conceder toda sua fortuna para o reconhecimento das grandes invenções no âmbito das ciências, para 
os cientitas que se destacassem nas descobertas nas áreas de Física, Química, Medicina e Literatura; além de promover o prêmio nobel da paz, destinado às pessoas que mostrassem empenho em prol da paz e da amizade entre as nações (TOLF, 1976).

\section{O surgimento do petróleo como ator preponderante na geopolítica}

Nenhum outro elemento transformou mais profundamente a história mundial, no últimos cem anos, do que as lutas para controlar, proteger e assegurar as reservas globais de petróleo. O poder político e econômico giram em torno da matéria-prima do recursos naturais e foram desenhados, durante muito tempo, pelos interesses em especial de duas nações: o Reino Unido e os Estados Unidos (ENGDAHL, 1992).

Com o intuito de ilustrar o panorama do surgimento do petróleo como ator preponderante da geopolítica, este tópico abordará brevemente o contexto do fim do século XIX e o início do Século XX até o fim da Primeira Guerra Mundial, tratando do Reino Unido, Estados Unidos, Alemanha e Rússia neste contexto histórico e suas relações iniciais com os recursos naturais.

O Reino Unido durante o Século XIX e início do Século XX era em todos os aspectos o maior destaque no poder político, militar e econômico do mundo. O ouro britânico, sob os cuidados do Banco da Inglaterra, foi a base para o papel da libra esterlina como a primeira 
fonte de crédito mundial, desde 1815. Entre os pilares que formavam o Estado-nação britânico estavam: como primeiro pilar, o controle britânico dos mares, e com ele o controle do comércio marítimo mundial, inspirados pelas estratégias geopolíticas de Sir Mackinder; como segundo pilar, a dominação inquestionável da Grã-Bretanha do sistema bancário internacional; e como terceiro pilar, gradativo de acordo com a passagem dos anos, era dominação geopolítica britânica sob o controle das mais proeminentes matérias-primas do mundo, tais quais o algodão, metais, café, carvão e, o novo 'ouro negro', o petróleo (ENGDAHL, 1992).

O poder hegemônico do Reino Unido no contexto global, no entanto, não se manteria absoluto por muito mais tempo. Como consequência direta da política imperialista britânica e de seu livre comércio, no início da década de 1870, uma profunda depressão econômica iniciou-se na Grã-Bretanha e durou até 1896. Neste contexto, surgiu um debate entre a elite britânica sobre como manter seu poder em um cenário de rápidas mudanças. A geopolítica do petróleo foi introduzida a este debate em 1882, somada a questão de como manter a supremacia naval britânica (ENGDAHL, 1992).

Rumo a última década do século XIX, as elites bancárias e políticas britânicas começaram a manifestar os primeiros sinais de preocupação sobre dois aspectos específicos do rápido desenvolvimento industrial na Alemanha. O primeiro sinal foi a emergência de um 
moderno e independente comércio alemão em sua frota naval militar ora, desde 1815 e do Congresso de Viena, a Marinha britânica detinha o poder incontestável dos mares. O segundo sinal foi a existência de um ambicioso projeto alemão para construir uma ferrovia ligando Berlim a Bagdad, então parte do Império Otomano. Em ambas as áreas, o desafio naval e da construção de uma infra-estrutura ferroviária que ligasse Berlim ao Golfo Pérsico, trouxe ao petróleo o papel de razão decisiva, tanto para os alemães quanto para os britânicos (ENGDAHL, 1992).

Em 1912, os Estados Unidos produziam mais de 63\% do petróleo do mundo, a Rússia 19\% e o México 5\%. A empresa AngloPersian Exploration Co da Grã-Bretanha ainda não estava produzindo grandes suprimentos de petróleo, mas a estratégia do governo britânico havia determinado que a presença britânica no Golfo Pérsico era essencial para o interesse nacional. Conforme o parágrafo anterior, a extensão implacável da Alemanha da linha ferroviária de Berlim-Bagdá desempenhou um papel significativo nesta decisão britânica. $\mathrm{O}$ aumento das divergências entre a economia decadente do Império Britânico e as economias industriais emergentes da Europa continental, sobretudo a do Reich alemão, criou o cenário para a eclosão da Primeira Guerra Mundial, em 1914. O papel do petróleo neste conflito já havia se tornado central, mesmo que poucos além de uma pequena elite de banqueiros de Londres e Nova York o tivessem notado, até anos depois (ENGDAHL, 1992). 
Um dos segredos melhor guardado da Primeira Guerra Mundial é a eminente falência do Tesouro britânico e das finanças do Império Britânico, na véspera do mês de Agosto de 1914, quando a Grã-Bretanha declarou guerra contra o Reich alemão. Uma análise da real situação financeira dos partidos que apoiavam a guerra revela um passado significativo de concessões secretas de crédito, conectados a detalhados planos de realocação do domínio das matérias-primas e das riquezas físicas do mundo inteiro após a guerra para a Grã-Bretanha, especialmente as das áreas do Império Otomano, que se acreditava possuir substanciais reservas de petróleo (ENGDAHL, 1992).

Os objetivos geopolíticos estratégicos da Grã-Bretanha, bem antes de 1914, incluíam não apenas o esmagamento de seu maior rival industrial, a Alemanha, mas, por meio da conquista de guerra, a garantia de controle britânico irrefragável sobre o petróleo, que já este havia provado ser o recurso de maior promessa para o desenvolvimento econômico. Em 1919, Mackinder classificou a conquista do mandato britânico sobre a Palestina como o resultado geopolítico mais importante da Primeira Guerra Mundial. Na primeira década do terceiro milênio, a geopolítica da Palestina, Israel e do Oriente Médio ainda estavam no coração da política do poder mundial, mesmo com as mudanças de jogadores neste jogo do poder (ENGDAHL, 1992).

Entre o início da Primeira Guerra e o fim desta, o petróleo foi reconhecido como a chave principal para o sucesso da revolução nas 
estratégias militares. Em uma época de guerra área, tanques móveis e de uma guerra naval mais veloz, a abundância de suprimentos do novo combustível se tornou cada vez mais essencial (ENGDAHL, 1992).

Neste mesmo contexto de surgimento de grandes potências no cenário internacional, no início de 1891, a Rússia começara a trabalhar intensamente em seu programa de desenvolvimento industrial, passando a vigorar tarifas protecionistas em sua economia e o projeto de construção de sua infraestrutura ferroviária. A malha ferroviária a ser construída nesta época mudaria significativamente a economia do país, pois ligaria toda sua extensão através da linha Transiberiana. Até então, este era o maior projeto ferroviário do mundo. O responsável por este programa era Sergei Witte, mais tarde tornaria-se ministro das finanças, que possuía profundos conhecimentos de economia e estreitas relações com a base franco-russa da época. Witte descrevia a construção da ferrovia Transiberiana como um elemento que criaria uma fermentação cultural até mesmo nos povos mais remotos do território russo (ENGDAHL, 1992).

A parte principal dos planos de Witte consistia em aproximarse da China com fins de comércio, mesmo que as rotas marítimas e os portos chineses estivessem sob o domínio britânico, com as rotas alternativas que a linha Transiberiana traria para as trocas comerciais (ENGDAHL, 1992). 
Desde o começo de seu mandato como ministro das finanças até sua saída em 1905, Witte transformou drasticamente a realidade russa de celeiro do comércio de grãos para Grã-Bretanha em uma moderna potência industrial. A construção de malhas ferroviárias tornou-se o negócio principal do país e induziram a transformação de todos os setores relacionados ao aço. Além disso, Witte nomeou um amigo próximo, o cientista Dimitri Mendeleiev, fundador da agroquímica, como chefe do novo escritório de pesos e medidas padrão, em que ele introduziu o sistema métrico para facilitar ainda mais o comércio com o continente europeu (ENGDAHL, 1992).

Seguiram-se as décadas e o entre guerras, deu-se a Segunda Guerra Mundial, também iniciada por motivos geopolíticos, dada a movimentação expansionista de Hitler e a insegurança gerada no cenário internacional com o abalo no equilíbrio de poder. Este tema, no entanto, será mantido para discussão em oportunidades futuras, visto que o objetivo do artigo planeja se ater ao estudo da geopolítica dos recursos naturais e não das relações geopolíticas das Guerras Mundiais, sendo a breve explanação das causas geopolíticas da Primeira Guerra Mundial satisfatória para ilustrar a importância dos recursos naturais energéticos, tal qual o petróleo, na economia mundial e como estes afetariam a economia global e as relações de poder até a pósmodernidade (ENGDAHL, 1992). 
Em 1919, o Império Britânico era o maior do planeta e seu domínio que abrangia um quarto de toda a superfície do globo. Com o fim da Segunda Guerra Mundial, apenas 30 anos mais tarde, em 1949, o Império Britânico se desintegrava em todas as regiões de suas colonias, como resultado de suas demandas por independência. Com a mudança na estrutura do poder global, com surgimento de Bretton Woods ${ }^{3}$ e o surgimento das novas potências que saíram poderosas do pós Guerra, inicia um período de bipolaridade no cenário internacional. De um lado havia os Estados Unidos, o responsável pela reconstrução da Europa com o Plano Marshall ${ }^{4}$, e sua investida imperialista e capitalista. Do outro lado estava a União Soviética aliada a Rússia, ameaça comunista, que vinha na corrida pelo poder desde o fim do Século XIX. A este período que se encerra somente no final da década de 1980, dá-se o nome de Guerra Fria (ENGDAHL, 1992).

\footnotetext{
3 Bretton Woods, sistema internacional de gestão monetária e cambial, que foi estabelecido em 1944 na Conferência Monetária e Financeira das Nações Unidas, realizada em Bretton Woods, New Hampshire (http://www.investopedia.com/terms/b/brettonwoodsagreement.asp).

${ }^{4}$ Plano Marshall, dada a ameaça da expansão comunista e da rápida deterioração das economias europeias, após o término da Segunda Guerra Mundial, o Congresso norteamericano aprovou a Lei de Cooperação Econômica em Março 1948 que consolidaria o financiamento de USD 12 bilhões para a reconstrução da Europa Ocidental (http://history.state.gov/milestones/1945-1952/marshall-plan).
} 


\section{A Geopolítica Russa do Gás Natural}

Um dos mais importantes desenvolvimentos energéticos dos últimos anos se estabeleceu em torno do domínio do gás natural. Enormes quantidades de gás de xisto, nos Estados Unidos, se tornaram comercialmente viáveis e transformaram as condições do país em relação ao uso deste recurso, tornando-o auto-suficiente em gás natural para o futuro. Este desenvolvimento repercutiu em todo o mundo, causando mudanças nos padrões de comércio e levando outros países da Europa e da Ásia a explorarem seus próprios potenciais de gás de xisto, o que acabou por pressionar acordos antigos, como os contratos de gás ligados ao petróleo e a forma com que o mercado do gás estava configurado na Ásia, na América do Norte e na Europa. Estas mudanças causaram impactos significativos na conjuntura do mercado do gás, como por exemplo, o enfraquecimento do domínio da Rússia no mercado europeu do gás (JOHNSTON; STROMQUIST, 2014).

A Rússia é um dos maiores líderes mundiais em produção de recursos energéticos primários, estando apenas atrás da China e dos Estados Unidos, e é conhecida por sua privilegiada posição geográfica para a producação de gás natural. O país detém a maior reserva deste recurso no mundo e só perde em produção para os Estado Unidos. Mesmo assim, a Rússia ainda é a maior exportadora global de gás natural. $\mathrm{O}$ setor industrial energético é um dos principais da economia 
russa, o que faz do país um líder global em exportação de energia e, ao mesmo tempo, um dos maiores consumidores mundiais, devido as necessidade de seu mercado doméstico (MITROVA, 2014).

Com sua incomparável infraestrutura transcontinental, localizada no coração da Eurásia, com 150 mil kilometros de gaseodutos, a Rússia se tornou a coluna vertebral do comércio de gás eurasiático, que poderia incluir a Europa, a África do Norte, a região do Mar Cáspio e o nordeste da Ásia. Ao reter o controle do transporte de gás desta região ademais de suas grandes reservas de gás a Rússia assume o papel de ator chave neste mercado, pois abastece toda a região do heartland ${ }^{5}$. Contando com $20 \%$ de todo abastecimento global de gás, a maior parte deste recurso russo é exportado para Europa e para Comunidade dos Estados Independentes e estima-se que, no futuro, haverá um crescimento significativo da exportação para a Ásia. Não é por menos que Rússia possui tanta influência nos preços e nas regras do jogo do nesta região, assim como expressivo poder geopolítico. Não somente na região do heartland, mas no mundo, a Rússia vem usando, há muitos anos, o gás como importante ferramenta geopolítica. E esta ferramenta, muitas vezes, é usada como arma geopolítica e instrumento

\footnotetext{
${ }^{5}$ Heartland, de acordo com a teoria do poder terrestre de H. J. Mackinder, os donos do poder mundial seriam aqueles que detivessem o Heartland que é o coração do mundo ou o meio da ilha do mundo, compreendida pela Eurásia (BONFIM, 2005).
} 
para obter influência em suas negociações internacionais, assim como para o fortalecimento de seu soft power (MITROVA, 2014).

Durante as últimas décadas, a economia russa aumentou sua relação de dependência na exportação de commodities. Somente em 2011 a exportação de petróleo somado aos seus derivados e o gás natural representaram mais de $67 \%$ de toda a exportação do país, ademais dos profits obtidos dos direitos aduaneiros e taxas de extração de óleo e gás provisionaram mais da metade de todos os rendimentos públicos. Estes rendimentos desempenham um papel importantíssimo para atender as despesas do orçamento nacional, tais quais verbas para o setor militar e social, além de manter o país funcionando economicamente. Os investimentos em óleo e gás são assim valorizados por serem a força motriz que multiplica investimentos ao criar demanda para outras esferas da indústria russa, além de assegurarem o desenvolvimento necessário para o crescimento econômico (MITROVA, 2004).

Dada a importância do setor energético para a economia russa, as decisões mais cruciais que o envolvem são tomadas pelo Estado em seus mais altos cargos. Especialmente para a indústria de óleo e gás, por serem de tamanha valia para o governo e seus rendimentos públicos. Atualmente, estas decisões são tomadas pelo Presidente Vladimir Putin e, sob sua tutela, ministros e outros secretarias executivas do Estados trabalham na elaboração de políticas para garantir não só a estabilidade, 
mas o crescimento do setor, que foi negativamente atingido pela crise econômica mundial em 2008 (MITROVA, 2014).

O Estado russo além de desenvolver as regras do jogo, também, interfere nas operações diárias que conduzem a indústria da energia. Naturalmente, o papel das empresas privadas que atuam no setor são relevantes, mas não tanto quanto o papel do Estado. $\mathrm{O}$ governo russo está completamente envolvido no setor energético, através de políticas que promovem recursos nucleares, energias renováveis e carvão; limitam o crescimento da demanda do gás; auxiliam a diversificação da mistura de combustível e também através de intervenções diretas no funcionamento do setor energético (MITROVA, 2014).

Estas ponderações econômicas e os recursos disponíveis configuram as consequencias geopolíticas de muitas maneiras. O fornecimento de gás ou a implementação de projetos de gás agem como instrumentos geopolíticos da Russia em algumas regiões, como a Europa, os Países da Comunidade Independente e os balcãs. Na era póssoviética, o gás era o maior instrumento de integração e o que dava condições para que a Rússia exercesse sua influência sob os países da Comunidade dos Estados Independentes. O gás era e ainda é, inclusive, o elemento mais importante nas negociações não somente com a Ucrânia e Bielorussia, mas praticamente com todos os países que fazem fronteira com a Rússia (MITROVA, 2014). 
Para o governo russo é interessante possuir este tipo de instrumento para negociações internacionais e para fortalecer sua autoridade. O Presidente Putin está pessoalmente monitorando a balança de poder entre os principais grupos concorrentes no mercado do gás, ou seja as empresas Gazprom, Rosfnet e Novatek, e é ele quem assume compromissos de longo prazo para extração e desenvolvimento da estrutura, envolvendo parceiros externos, e do processo de negociação de contratos (MITROVA, 2014).

Os recursos para desenvolver os campos de gás ou construir infraestutura de transporte são administrados pelas empresas privadas, mas é o governo que os controla, uma vez que os investimentos do país neste setor são muito altos, assim como a necessidade interna do país ao gás é crucial. O Governo russo não pode permitir erros na administração da extração e manutenção do gás, pois estes gerariam altos custos e prejuízos a estrutura econômica e social do país. Por este motivo todas as decisões governamentais que precisam ser tomadas e que abrangem o setor de óleo e gás na Rússia são cautelosamente avaliadas e com o envolvimento direto de Putin (MITROVA, 2014).

Conforme brevemente mencionado neste texto, a indústria do gás na Rússia foi impactada negativamente pela crise global. Sua produção e importação vinham aumentando progressivamente desde o início dos anos 2000 até a chegada da crise em 2009. A demanda demonstrou seguir mesmo ritmo com o crescimento do consumo 
interno em todos os setores da economia e das exportações crescentes para a Europa Ocidental, os a Comunidade dos Estados Independentes e a região da Ásia-Pacífico. A indústria russa de gás continua na mesma situação que se encontrava no começo da crise de 2009, o que traz sérias consequencias para o desenvolvimento deste mercado e para a dinâmica de seus preços (MITROVA, 2014).

No início dos anos 2000 a Rússia demonstrava 6-8\% de crescimento anual de seu PIB decorrente, principalmente, pela exportação de hibrocarbonetos, que teve boa repercussão mesmo durante a crise econômica global, mas atualmente há divergências a respeito da habilidade deste modelo baseado na exportação de hidrocarbonetos ser suficiente para manter a Rússia em um caminho contínuo de crescimento econômico. Em 2013, devido ao desaceleramento do consumo e a estagnação na demanda de investimentos, os resultados de crescimento da economia russa foram muito piores do que o esperado, mesmo com a alta no preço dos hidrocarbonetos (contaram com um crescimento de apenas 1,3\% em 2013, comparados com 4,5\% em 2012) (MITROVA, 2014).

Outros setores da economia também entraram em fase de estagnação. O capital de investimento industrial caiu de 14-16\% em 2012 para saldos negativos em 2013, o que levou muitos produtores a fecharem suas fábricas, o que pode gerar desemprego e maior tensão social, alegando que a situação estava muito pior que em 2008. Esta 
desaceleração do crescimento russo se dá, em partes, pela situação nos mercados externos. O enfraquecimento das empresas exportadoras foi acompanhado por uma queda doméstica na demanda por investimentos fixos com tendência negativa para o financiamento de capital de estado e empréstimos privados cada vez mais fracos (MITROVA, 2014).

$\mathrm{O}$ crescimento do Produto Interno Bruto experenciado pela Rússia no início dos anos 2000, resultou muito mais da alta internacional do preço do petróleo, do gás e outras matérias-primas do que desenvolvimento de outros setores de sua indústria. Por mais que a economia russa seguisse um rumo de crescimento nos últimos dez anos, sua estrutura se manteve praticamente inalterada, o efeito da modernização ainda é bastante modesto e a participação da indústria da alta tecnologia não cresceu (MITROVA, 2014).

A economia russa é extremamente vulnerável a variação de preços do petróleo e do gás. Com o mercado energético contabilizando $40 \%$ de sua exportação, aproximadamente 90\% do PIB russo é resultado do crescimento da indústria de petróleo e gás. Dada a dependência da Rússia nos rendimentos do petróleo, o país se aproximou da Organização dos Países Produtores de Petróleo (OPEP) com o intuito de estabelecer os preços do petróleo limitando a produção junto com quotas de produção da OPEP. No entanto, desde que os preços do petróleo foram estabelecidos em USD 25.00 (vinte e cinco 
dólares) por barril, a Rússia se recusa a continuar com quaisquer diretrizes coordenados pela OPEP (SEPEHRI, 2002).

\section{Putin e a Geopolítica Russa do Petróleo e do Gás desde os anos 2000}

Vladimir Putin se considera um adepto a uma democracia dirigida, como classifica o modelo de sistema político construído no controle de cima para baixo e que, na opinião de Putin, proporciona aos cidadãos russos muitos dos mesmos direitos legais que uma democracia desenvolvida proporciona. Putin considerou o fortalecimento do Estado Russo como prioridade e não a necessidade de fortalecer os direitos democráticos dos cidadãos russos. Para alguns autores, Putin considera o sistema político da Rússia pós-soviética como um trabalho em andamento (OLCOTT, 2004).

Putin buscou não somente a modernização do país, mas também a integração da Rússia à Europa, agregando uma liberdade econômica com uma política fechada, controlando os meios de comunicação de massas, ONGs, etc. Desde o ano em que tomou posse, a economia cresceu em um ritmo acelerado, recuperando-se em parte da crise econômica de 1998 onde a inflação atingiu níveis superiores a $80 \%$ ao ano. Com o governo de Putin, a Rússia passou a manter um 
nível de crescimento do PIB de cerca de $7 \%$ ao ano, o qual só diminuiria com a crise global de 2008 (GOLDMAN, 2008).

Durante seu primeiro mandato como presidente, Putin conseguiu retirar todo o time do ex-presidente Boris Yeltsin, que ainda dominava o panorama político russo no início de sua administração. Todos aqueles da "família" de Yeltsin foram repostos por tecnocratas com pouca conexão com o ex-presidente russo. A Rússia, durante a permanência de Boris Yeltsin na presidência, era um país em dificuldades econômicas e políticas em decorrência dos abalos causados pelo colapso da União Soviética, sem contar que Boris estava fisicamente frágil e doente durante grande parte de seus mandatos. Putin não gostou das condições em que herdou o país. Enquanto Boris Yeltsin dividiu o poder com o Parlamento Russo, Putin acreditava que a democracia parlamentar estava levando a Rússia para a direção errada, longe de um Estado forte que poderia proteger os interesses da população russa (OLCOTT, 2004).

Putin reconhecia os oligarcas do mundo dos negócios que contribuíram para definir a moderna vida política russa como um grupo bastante poderoso. Este grupo apoiava a Boris Yeltsin, tornando até mesmo possível a sua reeleição em 1996, e obtinha privilégios por isto. Este grupo tentou se aproximar de Putin da mesma forma que eram próximos de Yeltsin, no entanto, Putin os manteve a uma distância segura, podendo assim controlar a economia sem se ater a laços ou 
favores com a oligarquia que dominava a economia do país. A reação de Putin aos oligarcas não era simplesmente visceral, na verdade tentava desvincular o governo russo da influência e dependência dessas figuras proeminentes do mundo dos negócios (OLCOTT, 2004).

Putin não acreditava que estes oligarcas agiriam em benefício dos interesses da nação russa, mas sim em benefício inerentes as conveniências de todo oligarca, ou seja, seus próprios ganhos ao acumularem mais riquezas. O Presidente não queria que a Rússia caísse nas presas da doença holandesa ${ }^{6}$, que era um ponto de vista defendido por muitos petroleiros russos, que visavam a expansão de seus lucros, Putin, no entanto, acreditava que a dependência da Rússia no setor petroleiro e de gás natural deveria ser reduzida, afim de expandir os outros setores da economia russa (OLCOTT, 2004).

Putin defende que a propriedade russa sob recursos russos é extremamente crítica para a recuperação de sua economia e para retomar a posição de um agente preponderante nas relações internacionais. Ele não confia que a força do mercado global seja capaz de prover oportunidades econômicas e apoio social que transicionem hesitosamente a população russa de uma realidade comunista a uma realidade mais moderna, tal qual o modelo europeu de economia e

\footnotetext{
${ }^{6}$ Doença Holandesa, refere-se à relação entre a exportação de recursos naturais e o declínio do setor manufatureiro. A abundância de recursos naturais gera vantagens comparativas para o país que os possui, levando-o a se especializar na produção desses bens e a não se industrializar ou mesmo a se desindustrializar - o que, a longo prazo, inibe o processo de desenvolvimento econômico (PEREIRA, 2008).
} 
política. Putin acredita que a globalização prematura da economia russa traria ainda mais dificuldades para a maioria da população russa, assim como a concentração de muitas riquezas nas mãos de poucas pessoas que não têm nenhum interesse em incentivar o restabelecimento da economia russa (OLCOTT, 2004).

Para Putin, os recursos naturais russos não somente assegurarão o desenvolvimento econômico do país, como também garantirão posição de destaque para Rússia no cenário internacional. Neste discurso fica implícito que o Estado russo estabelece a indústria o petróleo e do gás como prioridade nacional. Em um artigo de sua autoria, Putin afirma que:

The stable development os the Russian economy inte coming years needs to be based on the planned growth of its component parts, including in first place, the potential os its mineral resources, which will serve as guarantee of the country's economic security and the development of the domestic processing industry is the mains source to turn Russia into a leading economic power with a high standard of living for the majority of the population in a relatively short period (PUTIN, 1999).

Apesar de suas ricas reservas de recursos naturais, a Rússia não será capaz de fornecer receita adicional suficiente para o Estado invista no desenvolvimento de sua própria indústria em um futuro próximo. $\mathrm{E}$ por este motivo, Putin aceita os investimentos estrangeiros, 
patrocinados pelo Estado, na indústria de extração de recursos naturais, incluindo o capital estrangeiro, pois este permite que o Estado obtenha vantagem na exportação de seus recursos naturais (OLCOTT, 2014).

As estratégia do Governo de Putin quanto a administração da indústria de petróleo e gás russa demonstra que o Estado não somente está ditando as regras do jogo neste mercado, mas também que este pode interferir nas atividades diárias que a compõem e a mantém funcionando. Mesmo que o papel das empresas privadas seja essencial, não é tão poderoso quanto o do Estado. A estratégia energética da Rússia até $2030^{7}$ é o documento básico que delimita as políticas russas neste ramo e estas visam usar os recursos energéticos da maneira mais eficiente, assim como usar o potencial deste setor para firmar o crescimento econômico do país, melhores condições de vida e melhor posição no mercado global (MITROVA, 2014).

Vladimir Putin almeja maximizar o papel da indústria do petróleo e do gás russa na forma com que a Rússia pratica sua política externa. Dentre suas estratégias está a vontade de se tornar um parceiro dos Estados Unidos, de cooperar de perto com a China e o Japão e de trabalhar mais ativamente com os governos da Europa Ocidental e

${ }^{7}$ Energy Strategy up to 2030, Documentos que foram preparados quando Putin assumiu a Presidência que esboçam as políticas energéticas a serem adotadas pelo Estado russo e que envolvem petróleo, gás, carvão e energia hidroelétrica. 
fixar-se no mercado de petróleo e gás, mediante a estruturação e desenvolvimento da indústria russa (OLCOTT, 2004).

Atualmente é possível ver os planos iniciais de Putin tomando forma no Oriente. Recentemente, conforme divulgado em uma matéria The Economist, Rússia, após mais de uma década de negociações, e China assinaram um acordo quanto fornecimento de gás natural, no valor de USD 400 bilhões. Este acordo representa não somente um passo importante no mercado de energia global, como também na geopolítica do planeta. $\mathrm{O}$ acordo sinaliza mudanças em várias questões globais chaves e não apenas no setor da energia. Além de conceder ao Presidente Vladimir Putin o direito de vangloriar-se frente as recentes sanções estabelecidas pelo ocidente contra a Rússia. Putin só irá cooperar com o ocidente quando perceber que os objetivos estratégicos da Rússia estão se consolidando. Este acordo minimiza a dependência da Rússia no fornecimento de gás para a Europa e ainda prova que Putin tem aliados regionais que se posicionam em seu favor quando tenta atenuar as sanções impostas pelos Estados Unidos pela tomada da Ucrânia. Além do mais, China e Rússia buscam afirmarem-se como potências regionais, o que torna a cooperação entre ambas bastante positiva.

Por fim, o presidente russo é uma peça importante nesse jogo de decisões políticas, direcionando os recursos para alcançar seus maiores objetivos e do ponto de vista de suas ações e de seu discurso, o 
faz com o intuito de melhorar a qualidade da vida e da economia do país, o que o torna apreciado internamente e lhe rendeu a reeleição. Enquanto os agentes internacionais buscam compreender as estratégias russas em suas recentes políticas, Putin age internamente tentando ganhar a confiança e restalecer a força russa no cenário internacional, desta vez não através da influência ideológica do comunismo, mas como uma potência moderna e industrializada em busca de inserção e cooperação neste cenário que é multilateral, multipolar e extremamente interdependente.

\section{Considerações finais}

O retorno da Rússia à cena internacional diplomática trouxe bastante desconforto para as potências ocidentais. Além das estratégias geopolíticas do recursos naturais em seu território e da maneira como trabalha com as empresas estrangeiras privadas que exploram seus recurso naturais, a Rússia vem mostrando interesse em expandir seu território de influência na região da Europa Oriental, sendo um exemplo deste a reconquista da Crimeia. Nos últimos anos, a Rússia já deixou algumas marcas em sua política internacional. Os Jogos Olímpicos de Inverno de Sochi, tinham por objetivo mostrar ao mundo que a Rússia era capaz de organizar um evento deste porte; o caso do asilo diplomático oferecido a Snowden mostrou que a Rússia seria o único 
país do mundo com condições de resistir as pressões dos Estados Unidos; e o caso da Síria deu a Putin o status de homem de Estado que conseguiu evitar a intervenção militar programada pelos Estados Unidos em território sírio (LEVESQUE, 2013).

Ao restaurar a autoridade do Estado russo, Putin ganha a confiança da população, apesar de seus desvios autrocráticos. Mediante o fortalecimento da Rússia na indústria da energia e do controle do Estado sobre esta, Putin coloca seu país em condições de assumir papel mais relevante em questões globais, pois detém o poder de manobras muito importantes na geopolítica do gás natural e do petróleo. Ainda que a União Européia tente depender menos do gás russo, bastou a Rússia cortar o gás da Ucrânia para acender a tensão nos países da Europa Ocidental. E a Rússia desde sempre usa os seus recursos naturais para tentar impor sua influência no cenário internacional.

Em um momento de multipolaridade, o que a Rússia vem buscando é a inserção gradual e bem estruturada no cenário internacional. Mesmo que a passos lentos e misturando o soft power com a tradicional relação de força, Putin compreende que o mundo hoje é extremamente interdependente e que já não se vive mais em um mundo bipolarizado com receio do comunismo. O capitalismo venceu e Putin não parece querer travar uma luta retrógrada que perdurou por quase toda a segunda metade do Século XX. Como acadêmico e presidente, Putin reconhece que é preciso modernizar a Rússia e 
fortalecer sua economia para que esta entre no jogo dos grandes global players e toda estas manobras recentes que Putin vem conduzindo na esfera regional são passos para a introdução russa no mercado global. Para Olcott, a Rússia ainda está se estruturando internamente para poder começar a cooperar com o ocidente e modernizar sua economia.

Embora a percepção tradicional global da Rússia seja negativa e caricaturada, até mesmo por conta de todo o histórico do país e de seu autoritarismo, é importante considerar que o que vimos acontecendo nesta conjuntura é um país defendendo seus interesses expansionistas e maximizando a atuação de seu poder. E os meios usados para que estes objetivos sejam alcançados não diferem das estratégias norteamericanas para manter seu poder geopolítico ao redor do mundo. Os conflitos do Afeganistão, do Iraque e da Líbia representam bem a semelhança com que ambas as potências possuem ao buscar defender seus interesses. A diferença está somente na aplicação da política de dois pesos, duas medidas com que os agentes internacionais ocidentais se habituaram a usar quando analisam e consideram as políticas internacionais Federação Russa (ZAJEC, 2014).

Por fim, o poder das nações neste mundo multilateral e interdependente tornou-se mais elusivo e o cálculo do poder ainda mais delicados e ilusório do que em outros tempos. Putin, ao calcular cuidadosamente a expansão o poder de seu Estado, considera a complexidade do mundo de hoje, joga poder com as empresas privadas 
dentro de seu território, observa os novos atores, expande suas conexões com quem é forte e está territorialmente próximo e busca terreno para se não se aventurar entrando prematuramente na economia globalizada, mas sim obter sucesso com esta manobra. Manobra que trará a Rússia de volta ao eixo das estrelas internacionais.

\section{Referências}

BANNWART, Antonio Carlos et al. Departamento de Engenharia de Petróleo. Disponível em: http://www.dep.fem.unicamp.br/drupal/?q=node/27_acesso em $12 \mathrm{de}$ Junho de 2014.

BONFIM, Uraci Castro. Geopolítica. Rio de Janeiro: Escola de Comando e Estado-Maior do Exército 2005. Disponível em < http://www.ensino.eb.br/cpeceme/docs/03_INTRO_GEOPOLITICA_2 011.pdf >.

CEPA/IF/USP.

Disponível em: http://cepa.if.usp.br/energia/energia1999/Grupo1A/historia.html, acesso em 12 de Junho de 2014.

ENGHDAL, William F. A Century of War: Anglo-American Oil Politics and the New World Order. Publicado por: Pluto Press. Londres, 2004. 
JONHSTON, Robert. STROMQUIST, Emily. The Russian Gas Sector: A Political Risk Case Study. Harvard Belfer Center Programs or Projects: The Geopolitics of Energy Project, January 2014.

LÉVESQUE, J., A Rússia Voltou. Le Monde Diplomatique Brasil, 02 de Dezembro de 2013.

MBP/COPPE/UFRJ. História do Petróleo. Disponível em: http://www.petroleo.coppe.ufrj.br/historia-do-petroleo, acesso em 12 de Junho de 2014.

MITROVA, Tatiana, Ph.D. The Geopolitics of Russian Natural Gas.

The James A. Baker III, Institute for Public Policy of Rice University, Houston, February 2014.

OLCOTT, Martha Brill. The Energy Dimension in Russian Global Strategy. The James A. Baker III, Institute for Public Policy of Rice University, Houston, October 2004.

SEPEHRI, Saman. The Geopolitics of Oil. International Socialist Review Issue 26, November-December 2002,

TARBELL, Ida M. The History of Standard Oil, Vol I; Cosimo, 1904. TOLF, Robert W. The Russian Rockfellers: Stanford University, 1976. 
ZEJAC, O., A Obsessão Antirussa. Le Monde Diplomatique Brasil, 03 de Abril de 2014. 